\title{
High frequency of pauses during intermittent locomotion of small South American gymnophthalmid lizards (Squamata, Gymnophthalmidae)
}

\author{
Elizabeth Höfling ${ }^{1}$ and Sabine Renous ${ }^{2}$ \\ 1 Departamento de Zoologia, Instituto de Biociências, Universidade de São Paulo, Rua do Matão, Travessa 14, ${ }^{\circ}$ \\ 321, 05508-900, São Paulo, SP, Brazil. E-mail: ehofling@usp.br. \\ 2 USM 302, Département d'Ecologie et Gestion de la Biodiversité, Muséum National d'Histoire Naturelle, 55 rue \\ Buffon, 75005, Paris, France.
}

\begin{abstract}
High frequency of pauses during intermittent locomotion of small South American gymnophthalmid lizards (Squamata, Gymnophthalmidae). We studied the locomotor behavior of two closely-related species of Gymnophthalmini lizards, Vanzosaura rubricauda and Procellosaurinus tetradactylus, that was imaged under laboratory conditions at a rate of 250 frames/s with a high-speed video camera (MotionScope PCI 1000) on four different substrates with increasing degrees of roughness (smooth perspex, cardboard, glued sand, and glued gravel). Vanzosaura rubricauda and P. tetradactylus are both characterized by intermittent locomotion, with pauses occurring with high frequency and having a short duration (from 1/10 to $1 / 3 \mathrm{~s}$ ), and taking place in rhythmic locomotion in an organized fashion during all types of gaits and on different substrates. The observed variations in duration and frequency of pauses suggest that in $V$. rubricauda mean pause duration is shorter and pause frequency is higher than in $P$. tetradactylus. The intermittent locomotion observed in $V$. rubricauda and P. tetradactylus imaging at $250 \mathrm{frames} / \mathrm{s}$ is probably of interest for neurobiologists. In the review of possible determinants, the phylogenetic relationships among the species of the tribe Gymnophthalmini are focused.
\end{abstract}

Keywords: Squamata, Gymnophthalmidae, Gymnophthalmini, Procellosaurinus tetradactylus, Vanzosaura rubricauda, pauses, locomotion behavior.

\section{Introduction}

Vertebrates can move with continuous locomotion, but they are able to suddenly change their speed or to completely come to a

Received 26 May 2004.

Accepted 18 November 2004.

Distributed December 2004. halt, thus introducing pauses between bursts of motion, which defines the specific pattern of intermittent locomotion that takes place "when the force an animal exerts to move itself through space is applied discontinuously and the pauses last longer than the non-powered phase of a single cycle of limb movement" (Kramer and McLaughlin 2001). This pattern occurs in terrestrial, aquatic, and aerial locomotion, but 
terrestrial organisms engaged in this discontinuous system of progression typically would come to a complete stop during the nonpowered phase.

In lizards, examples of intermittent locomotion are observed in viviparous forms, such as Lacerta vivipara (Avery et al. 1987, Avery and Bond 1989, Avery 1993), which spend 10$50 \%$ of their time in pause, its range depending on activity level, environmental complexity, and physical parameters. Individuals would change their patterns of intermittent locomotion as they face new substrate constraints in their natural habitat. Foraging includes an increase of pauses (up to $75 \%$ of the time) and a decrease of both motion periods and speed. In a study on the effects of recent feeding on the locomotor performance of juvenile Psammodromus algirus, Martin (1996) noticed that the individuals moved at lower speeds during bursts of locomotion after feeding, and also decreased the frequency of pauses. These pauses increase the chance of lizards visually perceiving prey or predators while walking (Avery et al. 1987, Avery 1993). When no longer displaying interest in further prey, pauses to search for prey are not needed anymore. In addition, since at this stage lizards are moving at a very slow speed, they could probably detect predators without being entirely still.

The possibility that pauses enhance recovery from fatigue was also proposed, but the physiological mechanisms concerned with it are not fully understood. Weinstein and Full (1999) showed that intermittent locomotion increases endurance in lizards. Gleeson and Hancock (2001) noted that the movement of lizards by a series of frequent bursts of locomotion may be no more expensive than continuous locomotion. The benefits of intermittent locomotion are probably dependent on the duration of the periods of movement and of the pause bouts. Kramer and McLaughlin (2001), in their review of the determining factors of these pauses, proposed the stabilization of the sensory fields. Avery (1993) showed that lizards were less likely to detect prey while moving, where vision and other senses are concerned. Avery et al. (1987) and Colishaw and Avery (1991) noted that when environments were visually more complex and prey more difficult to detect, foraging pause durations increased and movement distances decreased. Moving objects create sensorial stimuli associated with an increased probability of detection by both prey and predators. In this context, unpredictable movements or interruption of continuous progression create perturbations of the signal of detection, so that irregularity of occurrence and duration of pauses probably constitute a favorable strategy. Kramer and McLaughlin (2001) state that research in this area is just beginning.

Many questions concerning continuous versus intermittent locomotion remain unanswered. For example: (1) Have the pauses a regular or an irregular rhythm (frequency and duration)? (2) Are pauses effectively occurring during the non-powered phase of the limb cycle? (3) What is the effect of the substrate on pauses? (4) Do these pauses correspond to a phylogenetic feature?

Here we propose to study pause characteristics during intermittent locomotion in two closely related species: Vanzosaura rubricauda (Boulenger, 1902) and Procellosaurinus tetradactylus Rodrigues, 1991. Among the Gymnophthalmidae, the tribe Gymnophthalmini (Pellegrino et al. 2001) is composed of eight genera including fully limbed as well as reduced limbed forms (Rodrigues 1991a, 1995, 1996). The limbed V. rubricauda and P. tetradactylus are sibling genera (Rodrigues 1995, Pellegrino et al. 2001, Benozzati and Rodrigues 2003). Vanzosaura rubricauda is a widespread habitat generalist that occurs in several distinct physionomies and soil types. It is widely distributed in open areas, occurring in the Brazilian cerrados and caatingas, and in the Chaco. It is diurnal and its natural substrates include gravel, leaf litter, and sandy soils (Rodrigues 1991c, 1995, 1996). Comparatively, P. tetradactylus is endemic to 
relictual dunes and sandy soils in the semi-arid Brazilian caatinga. It is more specialized, living only in dunes on the banks of the São Francisco River, in Brazil. Both species can burrow, although $V$. rubricauda is never found in dunes of the banks of the São Francisco River where $P$. tetradactylus is present, but rather only in sandy soil (Rodrigues 1991c, 1995, 1996, Rocha 1998). This habitat difference provides the opportunity to comparatively examine the relationships between the ecological conditions peculiar to the habitats of these eyelidless microteiids and their behavior. To compare locomotion behaviors, the animals were studied under the same experimental conditions. Lizards were tested on standardized substrates characterized by increasing friction coefficients, since locomotion patterns of quadrupedal vertebrates vary in accordance to substrate conditions (Renous et al. 1995, 1998, 1999).

The high frequency of pauses of these very small lizards was disclosed by the use of highspeed video images of animals moving freely in a large field, comparative to their size.

To address the previous questions we analyze: gait patterns as expressions of limb coordination of the four limbs in locomotion, the frequency and the duration of pauses on the different substrates, and the timing of pauses in relation to this limb coordination. Finally, we note the distribution of such functional features in the microteiid lizards of the Gymnophthalmini tribe.

\section{Material and Methods}

Five adults Vanzosaura rubricauda (mean total length: $7.6 \mathrm{~cm}[7.7,7.1,8.0,7.8,7.4 \mathrm{~cm}]$ ) were used: two from Ibiraba, Bahia, one from Porto Primavera, Santa Rita do Pardo, and two from Aquidauana, Mato Grosso do Sul, Brazil. Three adults Procellosaurinus tetradactylus (mean total length: $6.2 \mathrm{~cm}[5.9,6.2,6.5 \mathrm{~cm}]$ ) were studied from Alagoado, Bahia, Brazil. After collection, the specimens were kept in terraria at the Departamento de Zoologia,
Instituto de Biociências, Universidade de São Paulo. One specimen of Psilophthalmus paeminosus Rodrigues, 1991 (Rodrigues 1991b) (total length: $8.2 \mathrm{~cm}$ ) from Santo Inácio, Bahia, Brazil, was filmed for comparison to the other species. It was kept in a terrarium at the Reptile Sector of the Fundação Parque Zoológico de São Paulo.

Most studies dealing with locomotion in lizards are based on larger animals than the microteiid here presented (e.g., Higham and Jayne 2004, Kohlsdorf et al. 2004). On practical grounds, it is impossible to deal in nature with locomotion parameters of such small animals as $V$. rubricata and $P$. tetradactylus. The research was therefore undertaken under laboratory controlled conditions using methods that were adapted to deal with the small size of the animals reported here. Treadmills (Reilly and Delancey 1997a,b, Van Damme et al. 1998), for instance, could not be used here.

Specimens placed inside a large plastic box $\left(40^{\prime} 50 \mathrm{~cm}\right)$ were imaged at 250 frames/s (field: $30{ }^{\prime} 40 \mathrm{~cm}$ ) with a MotionScope PCI 1000 highspeed video camera set on tripod; the animals were placed on four different substrates with increasing degrees of roughness (smooth perspex, cardboard, glued sand, and glued gravel). A $1 \mathrm{~cm}$ scale was included in the field of view as a reference for the calculation of distances. Room temperature (ca. $26^{\circ} \mathrm{C}$ ) was kept as close as possible to average temperatures prevailing in the specimens' habitats. The specimens were returned to terraria between filming sequences to reduce the stress produced in psammophilous animals by artificial lighting. They were imaged after having fasted for around two hours to avoid the effects of recent feeding on locomotor performance.

When the animals were placed inside the box, we observed a waiting time of adaptation to the new conditions before filming (from 10 to $20 \mathrm{~min}$, according to the specimen). After frequent and fast escape trials around the walls of the box, the animals generally pass through a motionless phase before an exploring behavior 
and sequences of more or less fast crossing of the box, often along its main diagonal axis. These long crossings represent the studied sequences.

From 179 sequences captured we selected 88 showing a straight locomotion pattern. Each sequence included five to $30 \mathrm{limb}$ cycles. To establish gait diagrams the sequences were analyzed frame by frame using SigmaScan image processing software running on a PC computer and data saved in Excel. Gait diagrams were generated using the method of Marey (1891), in which successive time contact intervals (time that a foot is on the ground) of the four limbs along a sequence of motion were expressed. This quantifies the relative duration of stance and swing phases of the four legs.

The gaits were defined according to Hildebrand (1966) as symmetrical (walk, pace, and trot), when the footfalls of two legs of a pair (anterior and posterior pairs) are evenly spaced in time. Two quantitative parameters define these distinct symmetrical gaits: the contact interval (or percentage of cycle that each foot is on the ground) and the percentage of the cycle that a fore footfall follows the hind footfall on the same side of the body (Hildebrand 1966). The first parameter represents speed because it varies with the rate of locomotion. The second relates the action of one pair of feet to that of the other. In the pace two legs on the same side of the body move in phase. In the trot, diagonally opposite legs (RF, right fore limb, and LH, left hind limb) (LF, left fore limb, and $\mathrm{RH}$, right hind limb) are in phase. The walk is characterized by successive footfalls of the four feet equally spaced in time. The walk and the walking trot use a lateral sequence when the fore footfall follows the hind footfall on the same side of the body. Also, the same gaits use a diagonal sequence when the fore footfall follows that of the hind footfall on the opposite side of the body.

The timing and duration of pauses are indicated on each gait diagram along the sequence of motion. Only pauses occurring during displacement were used to construct gait diagrams. Different pause patterns were recognized in gait diagrams based on the moment at which pauses intervened during limb motions. On each sequence, for each specimen, the duration of each pause was measured and subtracted from the stance duration phase of each limb to have the true limb period (successive stance and swing phases) and the limb frequency (inverse function of the period). This method also permitted calculating a true speed or active velocity $(\mathrm{cm} / \mathrm{s})$ as the product of stride length and limb frequency. In addition, for all sequences and substrates the following were calculated: (a) number of pauses in a sequence, (b) distance covered in centimeters, (c) total duration of each displacement in seconds, (d) total duration of pauses in seconds (or pause duration) obtained by addition of all the pauses of the sequence, (e) duration of each active displacement, calculated by the difference c-d, (f) average speed including pauses, (g) average speed excluding pauses, or active speed, (h) pause frequency as the number of pauses per second (number of pauses divided by total displacement time, a/c), and (i) mean pause duration as the time of pause per second of displacement, a/c.

Calculations were performed and graphs were prepared using Excel 2002 (Microsoft Software) and Prism 3.0 (GraphPad Software, Inc.). For both animals, in order to verify the existence of relationships between the sequence duration, as dependant variable, and the pause duration, as independent variable, we used standard least-square techniques of regression analysis (values for $\mathrm{F}$ and $\mathrm{P}$ ). To examine the relationship between number of pauses, as dependant variable, and active speed, as independent variable, for each type of substrates, we used a log transformation before estimating the least-square regression equations. For each regression, we provided the value of the coefficient of correlation and the estimation equation, derived using standard software.

Since the duration of the limb cycle varied 
with speed as well as with substrates, we used a theoretical model to show the timing of pauses in relation to limb coordination. This model, using the classical representation of gaits (Hildebrand 1966), is based on fictitious units of time, to adapted to each type of pause and limb coordination pattern.

\section{Results}

\section{Patterns of Gaits (Limb Coordination)}

Vanzosaura rubricauda and Procellosaurinus tetradactylus have nearly the same body proportions: $16 \%$ of total length corresponding to the distance between the extremity of the snout and the root of the fore limbs, $19.5 \%(P$. tetradactylus) and $21 \%$ (V. rubricauda) to the distance between girdles, and the rest to the tail. Both species are characterized by intermittent locomotion and few cycles were unaffected by pause phases. In V. rubricauda, only 64 of the 879 cycles analyzed lacked pauses as did 14 of the 239 cycles in P. tetradactylus. Pauses occur during the trot and walking trot (Figure 1), or the walk, whatever the sequence duration and displacement speed.

On all four substrates, individuals of both species presented gaits ranging from trot to pace through walking trot, characterized by a lateral sequence (sensu Hildebrand 1966). The active displacements corresponding to these gaits were slow for both species (from 2 to $42 \mathrm{~cm} \mathrm{~s}^{-1}$ ) according to the size of studied lizards. However, V. rubricauda is generally faster (range: 2 to $42 \mathrm{~cm} \mathrm{~s}^{-1}$ ) than P. tetradactylus (range: 3 to $27 \mathrm{~cm} \mathrm{~s}^{-1}$ ). It is important to emphasize that these very small animals have the same body proportions and size. Therefore absolute speed can be directly compared.

\section{Frequency and Duration of Pauses}

On all substrates, total pause duration shows a linear increase with total duration of the displacement sequence for both $V$. rubricauda
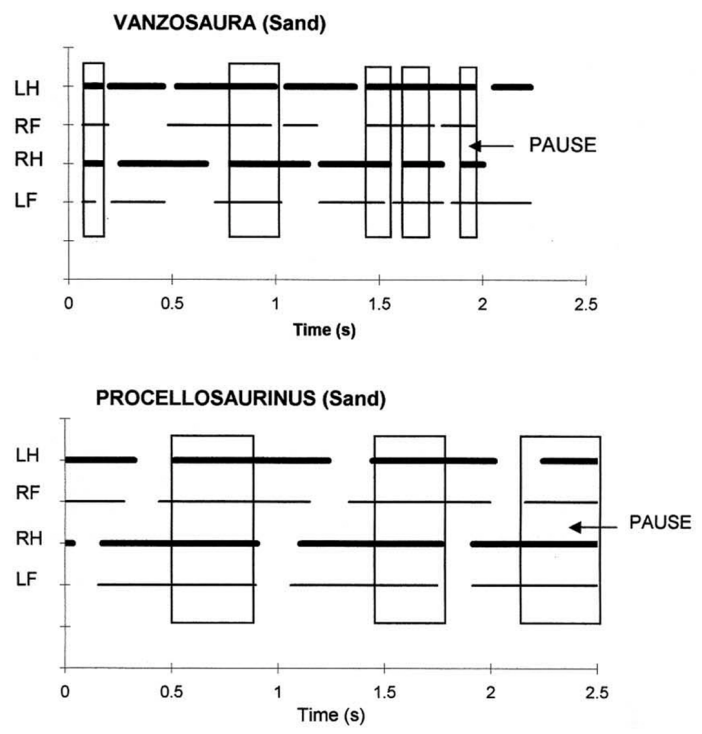

Figure 1 - Example of intermittent locomotion in Vanzosaura rubricauda and Procellosaurinus tetradactylus on sand. $\mathrm{LH}$ and $\mathrm{RH}$, left and right hind limbs; LF and RF, left and right fore limbs. Horizontal bars represent stance phase: black bars, hind limbs; grey bars, fore limbs. Spaces between bars represent swing phases. Vertical squares delimit pause times. Both diagrams in the same scale of 2.5 seconds.

$\left(\mathrm{r}^{2}=0.85, \mathrm{~F}=365.8, \mathrm{P}<10^{-6}\right)$ and $P$. tetradactylus $\left(\mathrm{r}^{2}=0.86, \mathrm{~F}=116.7, \mathrm{P}<10^{-6}\right)$ (Figure 2). This relationship is not obvious because it expresses that the pauses were regular and closely related to rhythmic activity of limbs. During a sequence of displacement, the number of pauses decreases with the increase of active speed (Figure 3 ) in both species, except curiously for the substrates corresponding to more natural conditions: gravel for $V$. rubricauda (non-significant test: $\mathrm{r}^{2} \sim 0, \mathrm{~F}=2.08 \times 10^{-5}$, $\mathrm{P}=0.99$ ) and sand for $P$. tetradactylus (nonsignificant test: $\left.\mathrm{r}^{2} \sim 0, \mathrm{~F}=0.76, \mathrm{P}=0.094\right)$. Under these latter conditions, and in spite of the previous global correlation (Figure 2), the number of pauses does not seem clearly related to active speed. The statistic test is significant on cardboard $\left(\mathrm{r}^{2}=0.58, \mathrm{~F}=44.95, \mathrm{P}<10^{-6}\right)$, on 


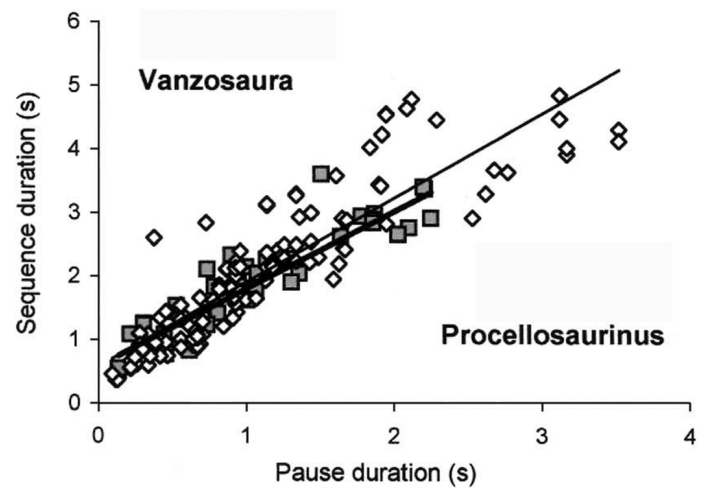

Figure 2 - Relationships between total pause duration and total duration of sequence of displacement: diamond-shaped white points for Vanzosaura rubricauda, grey squared points for Procellosaurinus tetradactylus.
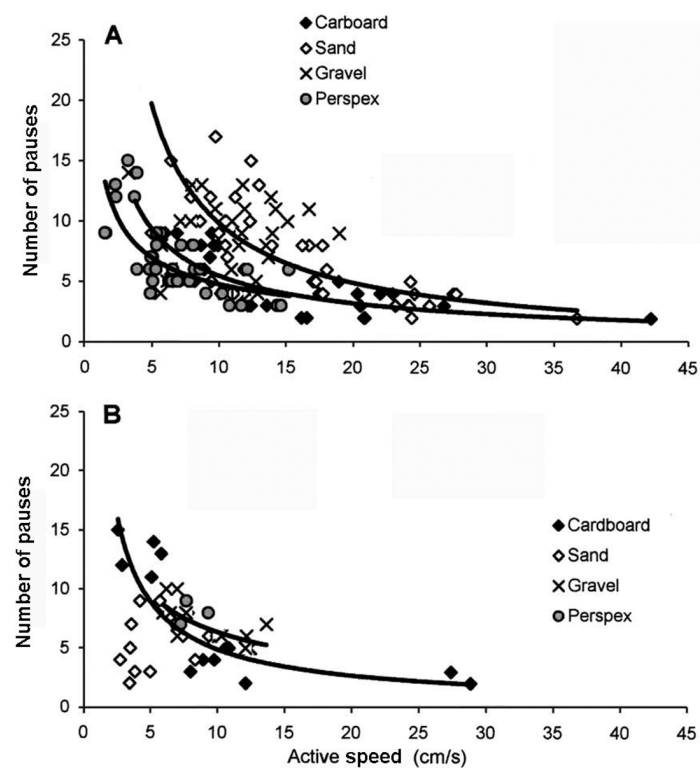

Figure 3 - Relationship between number of pauses and active speed $(\mathrm{cm} / \mathrm{s})$ of the animal during the sequences of displacement on all substrates. (A) Vanzosaura rubricauda, (B) Procellosaurinus tetradactylus.

sand $\left(\mathrm{r}^{2}=0.75, \mathrm{~F}=42.13, \mathrm{P}<10^{-6}\right)$ and on perspex $\left(\mathrm{r}^{2}=0.72, \mathrm{~F}=38.23, \mathrm{P}<10^{-6}\right)$ for $V$. rubricauda. It is also the case for $P$. tetradactylus on carboard $\left(\mathrm{r}^{2}=0.84, \mathrm{~F}=32.15, \mathrm{P}=\right.$
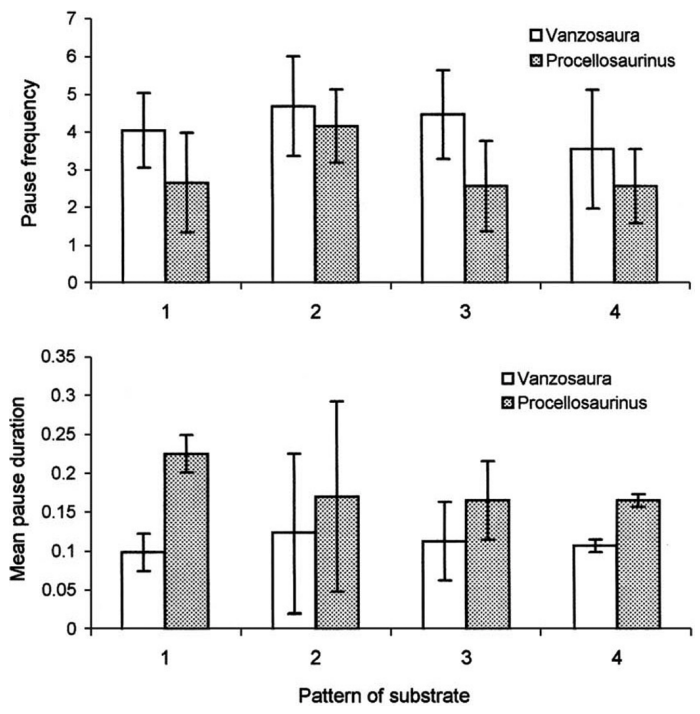

Figure 4 - Relationships between patterns of substrate (1, cardboard; 2, sand; 3, gravel and 4, perspex) and pause frequency (number of pauses per second) on one hand, and pause duration on the other hand. Values are means (standard deviations indicated by vertical lines limited by horizontal bars).

$0.00007)$ and gravel $\left(\mathrm{r}^{2}=0.71, \mathrm{~F}=12.33, \mathrm{P}=\right.$ $0.004)$. On perspex the relation showed to be non-significant, probably due to the small number of available data of the experiment $\left(\mathrm{r}^{2}=\right.$ $0.47, \mathrm{~F}=0.86, \mathrm{P}=0.422$ ).

On all substrates, V. rubricauda showed a higher pause frequency comparatively to $P$. tetradactylus (Figure 4). In the former species, this frequency reaches the highest value on sand and the lowest on perspex. In the latter species, this frequency is more elevated on sand. In the same manner, the pause duration of $P$. tetradactylus is longer than in the displacement of $V$. rubricauda. In $P$. tetradactylus this pause duration is longest on cardboard and shortest on sand, whereas the situation is the reverse for $V$. rubricauda. We must also note the great variability of data on sand, particularly for $V$. rubricauda, in agreement with the previous results (Figure 3). These results suggest different patterns for each species: shorter pause duration 
with higher pause frequency for Vanzosaura rubricauda and longer pause duration with lower pause frequency for Procellosaurinus tetradactylus.

\section{Timing of Pauses in Relation to Limb Coordination}

On all substrates, pauses occur at precise moments in the coordination of the four limbs, according to the gaits and displacement speed. A theoretical model allowed for synthesizing the data and specifying the start and stop of pauses in relation to the beginning and end of the phases (stance and swing) of the cycle of the four limbs (Figure 5).

In the trot (for 94\% of the cases), these pauses began with the touchdown of diagonal limbs $(\mathrm{LF} / \mathrm{RH})$, when the opposite diagonal limbs (LH/RF) was also previously in contact, and ended at the takeoff of these latter diagonal limbs (LH/RF) (Figure 5A,B; pattern 1). Ocasionally (for $4 \%$ of the cases), the stance duration of a diagonal pair of limbs (LH/RF) can be interrupted by the contact phase of the opposite diagonal pair (LF/RH) (Figure 5C,D; pattern 2). These two patterns (1 and 2) were sometimes (for $2 \%$ of the cases) combined during the stance of diagonal limbs (Figure 5E).

In the walk or walking trot (Figure 5F; pattern 3) (for $86 \%$ of the cases), a pause began with the touchdown of one hind limb (LH) and ended with the takeoff of the fore limb on the same side of the body (LF). Sometimes, two pauses, following this pattern, intervened during stance of diagonal limbs (Figure 5G) (for 10\% of the cases). The first pause, for example, began with the touchdown of the left hind limb (LH) and ended with the takeoff of the left fore limb (LF). The second began with the touchdown of the right hind limb (RH) and ended with the takeoff of the right fore limb (RF). A special case (Figure $5 \mathrm{H}$ ) (for $4 \%$ of the cases) occurred when one of the fore limbs presented an additional contact phase during the stance for other limbs.

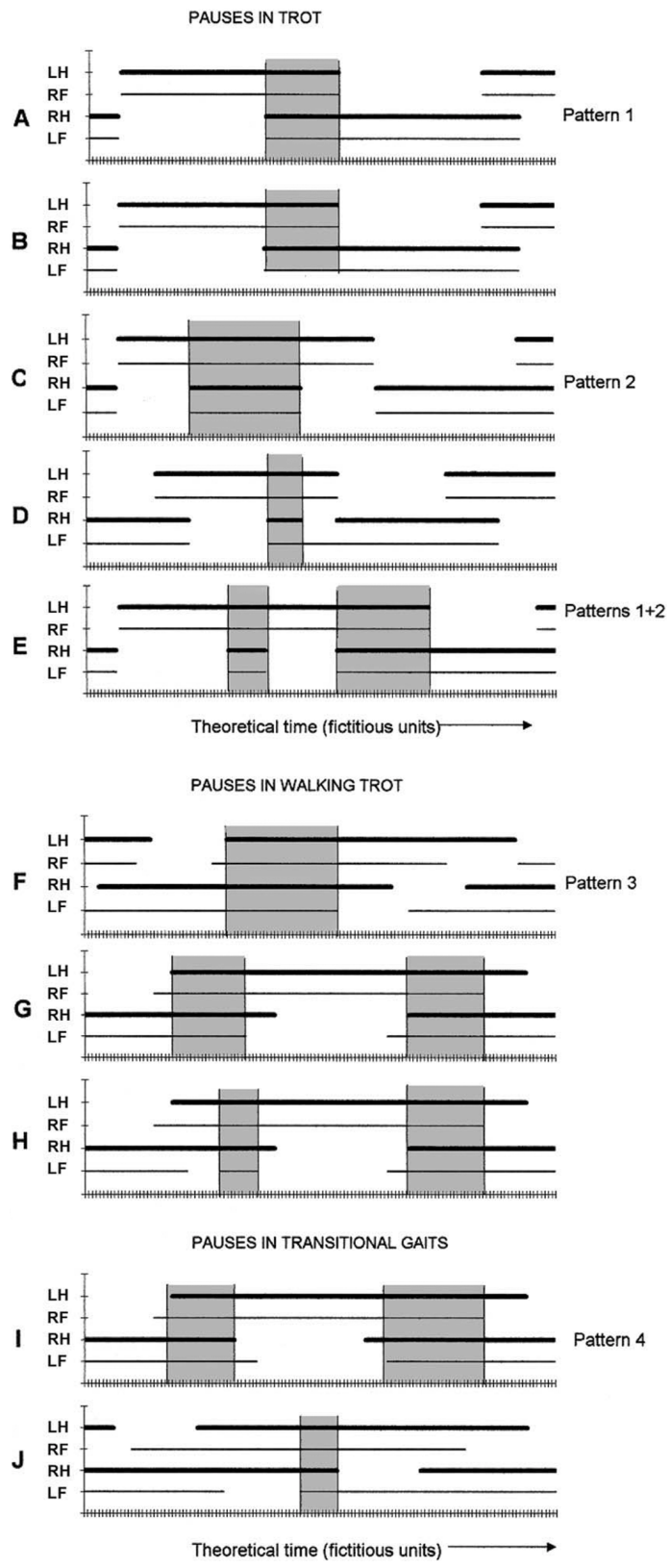

Figure 5 - Theoretical representation of the pause patterns in diverse mode of coordination of the four limbs, trot, walking trot and transitional gaits. $\mathrm{LH}$ and $\mathrm{RH}$, left and right hind limbs; $\mathrm{LF}$ and $\mathrm{RF}$, left and right fore limbs. Bars represent stance phases: black bars, hind limbs; grey bars, fore limbs. Vertical lines delimit the periods of pause. The horizontal regular graduations of fictitious units indicate a theoretical time. 
In transitional gaits, when coordination of limbs within each diagonal is inverted and the animal is in a temporary non-symmetrical regime, the place of pause slightly differs. The pause begins with the touchdown of one hind limb and ends with the takeoff of the other. Under these conditions, pauses also begin with the touchdown of one fore limb and stop with the takeoff of the other (Figure 5I; pattern 4). Sometimes, a pause was started with the touchdown of a limb of a diagonal pair, and stopped with the takeoff of the other limb of the same pair. This pause interrupted the stance of the limbs of the other diagonal pairs (Figure 5J).

A double S-bend in the body axis favors use of the walking trot and trot. Pauses were always seen to occur when the trunk was fully extended between two opposite flexions, coinciding with more or less synchronous movements of each diagonal pair of limbs.

Vanzosaura rubricauda used all patterns on cardboard, gravel, and sand, although pattern 2 was not utilized to a significant extent on perspex. Procellosaurinus tetradactylus mainly shows patterns 1 and 2, scarcely using pattern 3 on sand and pattern 4 on gravel.

\section{Phylogenetical Data}

The morphofunctional similarity expressed by the gait and pause patterns in both species could reflect phylogenetic relations among quadrupedal forms of the tribe Gymnophthalmini (Rodrigues 1995, 1996, Pellegrino et al. 2001, Benozzati and Rodrigues 2003) (Figure 6). Further evidence is provided by Psilophthalmus paeminosus, which also belongs to this group (Pellegrino et al. 2001), and presents pause patterns similar to those of $V$. rubricauda and P. tetradactylus. However, because only one specimen of $P$. paeminosus could be filmed, it was not possible to establish locomotion parameters for the species. Moreover, Micrablepharus maximiliani, which

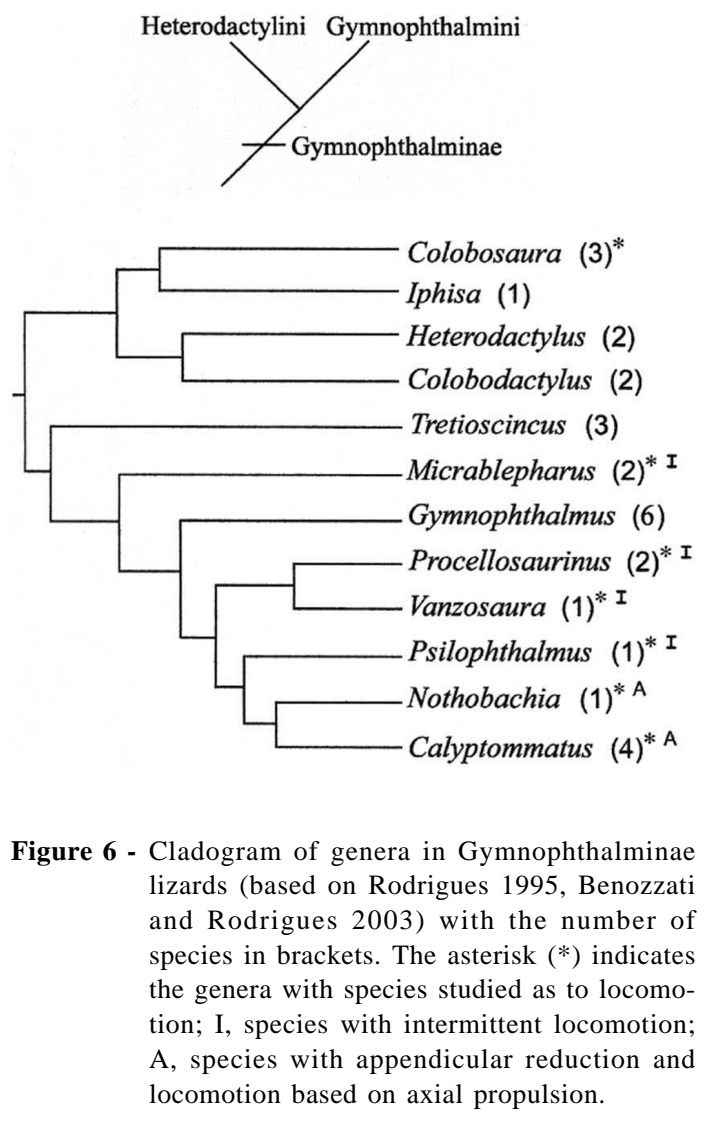

had been studied previously (Renous et al. 1999), also presents intermittent locomotion on sand and gravel, albeit less organized in that pause frequency and highly variable duration. In comparison, Colobosaura modesta (Renous et al. 1999), a heterodactyline (Pellegrino et al. 2001), presents locomotion without pauses. In two other species of Gymnophthalmini (Nothobachia ablephara and Calyptommatus leiolepis), with a distinct reduction of locomotor limbs, the relative functioning of limbs and vertebral axis appears to be different in that the vertebral axis predominates by acting as the main driver of locomotion to the detriment of quadrupedal specialization (Renous et al. 1995, 1998). 


\section{Discussion}

This study describes an original locomotor behavior in Gymnophthalmid lizards, and documents relationships of motor coordination of the four limbs and characteristics of pauses.

Are the pauses of Vanzosaura rubricauda and Procellosaurinus tetradactylus similar to the pauses of the other lizards? This question is essential and we must try to answer it. Interruptions during displacement in lizards have been observed a great many times (M. T. Rodrigues, pers. com.), but they consist of longer pauses during locomotion, of the kind also observed in $V$. rubricauda and $P$. tetradactylus. Effectively, pause duration in intermittent locomotion observed in lizards by previous papers (Avery et al. 1987, Avery and Bond 1989, Avery 1993) is considerably higher (about $10 \mathrm{~s}$ according to Weinstein and Full 1999) than those seen in $V$. rubricauda and $P$. tetradactylus (lower than $1 \mathrm{~s}$ ). The use of a high speed video camera running at 250 frames/s permitted an accurate investigation of these high frequency pauses. We must add that the animals studied are not in the size range of lizards analyzed in these previously cited papers. The high frequency pauses described here could be in relationship to the very small size of the lizards. To verify this hypothesis, a similar study should be done with other forms, for example, Australian or African species of Scincidae (e.g. Carlia spp.), which have similar morphological and ecological adaptations.

Are pauses correlated to limb movement in locomotion? In both species, V. rubricauda and $P$. tetradactylus, the linear increase of total pause duration with the total duration of the sequence of progression probably furnishes the first proof of a relationship with rhythmic activity of limbs. Indeed, this relation suggests that a particular phase of the four limbs coordination is disrupted by a pause, regularly along the sequence of displacement. Pauses are regular and random-inserted in the rhythmic activity of the four limbs. The number of pauses decreasing with the increase of speed provides another proof of this previous relationship. Pause-rhythmic limb activity also decreases, probably due to the stance duration (Duty Factor) of each limb, and pauses often occur at the end of this phase. The non-significant correlation coefficient found between number of pauses and active speed on rather natural substrates for $V$. rubricauda (gravel) and $P$. tetradactylus (sand) could indicate the existence of a different functional dependence (e.g., a nonlinear association pattern) between the parameters. A preferential use of one of the determinant factors of speed (speed resulting from limb frequency and stride length) could be the motive. Effectively, P. tetradactylus, endemic of relictual dunes and sandy soils of the banks of the São Francisco River, further increases its stride length on sand comparative to other substrates, where limb frequency is preferred.

Do the pauses occur during the nonpowered phase of the limb activity? It is difficult to answer affirmatively. In the trot, in pattern 1 , when pauses start with the touchdown of a pair of diagonal limbs and stop with the takeoff of the opposite diagonal pair, they determine the limit of the stance and swing phases. Because stance is at its beginning or its end, we may consider that the limbs are not in full propulsive conditions. In pattern 2 , for one pair of diagonal limbs, the pause can represent an "accident" during the swing phase. However, this concerns the powered stance phase of the other pair of diagonal limbs. It is the same for the diverse associations of these previous patterns. In the walking trot, contrary to the trot, pauses occur during the nonpowered phase for only one or two limbs.

Pauses certainly occur in the same manner in both species in relation to rhythmic limb activity and coordination of limb movements. Pause patterns are determined by patterns of gait, being introduced by touchdown for a hind limb, either in phase (trot) with or out of phase with (walking trot and walk) the diagonal fore limb. Takeoff of an ipsilateral fore limb interrupts the pause and reintroduces active locomotion. 
Ipsilateral limb motion might not be the only factor responsible for pause introduction and regulation: the vertebral axis may also play a role, since the body curvature in the horizontal plane favors the achievement of stride length among lizards (Jenkins and Goslow 1983). The double S-bend, all the more conspicuous in longer trunks, favors the use of the trot (Pridmore 1994 [1995]). Extension of the vertebral axis separates successive flexions in opposite directions and corresponds to the intervention of each diagonal pair of limbs. The pause that occurs during extension ceases when another flexion begins.

We can probably find one of the determinants of this motionless stage in a process of forward progression in the motor control of the movements of the axial osteomuscular system. It is also possible that this control introduces a temporary inhibition of the motor frameworks governing the rhythmicity and the coordination of the limbs. This is a question worth studying and of interest to neurobiologists.

Why are there original patterns of pauses in the studied species? The difference of styles observed for the pauses between both species, i.e., shorter pause duration with higher pause frequency in Vanzosaura rubricauda and longer pause duration with lower pause frequency in Procellosaurinus tetradactylus, could suggest different strategies in behavior and physiological functions: system of signalization or defence, visual perception of the environment, metabolical requirements and pulmonary ventilation.

In a general review of intermittent locomotion Kramer and McLaughlin (2001) concluded that this discontinuous mode of locomotion requires a greater expenditure of energy than the continuous mode, owing to the deceleration and acceleration entailed by pauses. It may even become disadvantageous when the pause and displacement phases are very short. Maybe it is for this reason that the number of pauses decreases in $V$. rubricauda and $P$. tetradactylus with the increase in speed. However, Gleeson and Hancock (2001) show that metabolic energy expenditure in lizards and rodents due to intermittent locomotion are less per unit distance covered than estimated expenditure for continuous displacement. The gait of these vertebrates suggests that it is not more costly to go from one point to another in a series of short bursts than to do so all at once by regular displacement. Kramer and McLaughlin (2001) believe these pauses may be an ill-understood means of recovering from fatigue or possibly of stabilizing the visual field. A recent study of Trouilloud et al. (2004) showed that "similarities between pausing and head raising in chipmunks suggested that pausing during locomotion also serves to increase vigilance" by a stabilization of the visual field, in order to facilitate the detection of moving objects. Avery (1993) showed that lizards are less able to detect the approach of prey when in movement. Generally speaking, displacement may reduce the ability of information sensing systems to discern disturbances in a complex environmental field. Indeed, according to Kramer and McLaughlin (2001), the duration of pauses and active locomotion phases decreases as the environment becomes more complex. Rapid changes in direction between pauses are facilitated by a walking trot with lateral sequences, which greatly enhance the opportunities for maneuvering (Hildebrand 1985).

Are the pauses in relation to ventilation? We know that the respiratory cycles of lizards are influenced by locomotion, as shown by research on Varanus exanthematicus and Iguana iguana (e.g., Mitchell et al. 1981, Wang et al. 1997). According to Carrier (1987, 1989, 1990), lung ventilation and the action of hypaxial muscles gradually decrease during locomotion. The lizard species analyzed here, Vanzosaura rubricauda and Procellosaurinus tetradactylus, are considerably smaller than $V$. exanthematicus and I. iguana, and therefore consume far more energy (if we refer to energy consumption by gram of tissue). However, without data about this subject regarding $V$. rubricauda and $P$. 
tetradactylus, we think that pause duration are very much shorter than ventilatory cycle duration. Pauses are probably much too short to contribute to an increase of lactate clearance or to support locomotion at speeds greater than the maximum aerobic speed. Vanzosaura rubricauda and P. tetradactylus are psammophilous animals and live under natural conditions inside the substrate (microhabitat).

Among all the hypotheses possible to explain this particular intermittent locomotion seen in $V$. rubricauda and $P$. tetradactylus, phylogenetically close relationships (Rodrigues 1995, 1996, Pellegrino et al. 2001, Benozzati and Rodrigues 2003) are the most consistent data. However, in order to conclude whether this type of intermittent locomotion is a sign of phylogenetic relationships or a form of convergence that appears in different groups of Sauria (intermittent locomotion has been observed in a lacertid, Lacerta vivipara by Avery et al. 1987), more data on the locomotion patterns of Squamata are needed (Van Damme et al. 2003).

\section{Acknowledgements}

We are grateful to A. Beda and F. L. Franco for collecting specimens; F. F. Curcio and F. Molina for keeping the animals in the laboratory, and A. Abourachid for assistance with imaging. We would also like to thank M. T. Rodrigues for collecting specimens and for suggestions on this research, P. E. Vanzolini, P.A. Otto and three anonymous referees for critically reviewing the manuscript, Vincent Bels and Leslie Decker for assistance with statistics, and to Antonio D'Avila. This research project was supported by FAPESP (Fundação de Amparo à Pesquisa do Estado de São Paulo: Proc. 2000/11318-1), CNPq (Conselho Nacional de Pesquisa e Desenvolvimento: Proc. 303926/ 85-6 [RV]) and FRE 2696 (CNRS/MNHN/ UMPC-P6/Collège de France). We thank IBAMA for the collection license (number 193/ 2001).

\section{References}

Avery, R. A. 1993. Experimental analysis of lizard pausetravel movement: pauses increase probability of prey capture. Amphibia-Reptilia 14: 423-427.

Avery, R. A. and D. J. Bond 1989. Movement patterns of lacertid lizards: effects of temperature on speed, pauses and gait in Lacerta vivipara. Amphibia-Reptilia 10: $77-84$.

Avery, R. A., C. F. Mueller, J. A. Smith, and J. Bond 1987. The movement pattern of lacertid lizards: speed, gait and pauses in Lacerta vivipara. Journal of Zoology 211: 47-63.

Benozzati, M. L. and M. T. Rodrigues 2003. Mitochondrial restriction-site characterization of gymnophthalmid lizards. Journal of Herpetology 37: 161-168.

Carrier, D. R. 1987. Lung ventilation during walking and running in four species of lizards. Journal of Experimental Biology 47: 33-42.

Carrier, D. R. 1989. Ventilatory action of the hypaxial muscles of the lizard Iguana iguana: a function of a slow muscle. Journal of Experimental Biology 143: 435-457.

Carrier, D. R. 1990. Activity of the hypaxial muscles during walking in the lizard Iguana iguana. Journal of Experimental Biology 152: 453-470.

Colishaw, G. and R. A. Avery 1991. Visual stimuli and spontaneous locomotor patterns of common lizards, Lacerta vivipara. Herpetological Journal 1: 577-579.

Gleeson, T. T. and T. V. Hancock 2001. Modeling the metabolic energetics of brief and intermittent locomotion in lizards and rodents. American Zoologist 41: 211-218.

Higham, T. E. and B. C. Jayne 2004. Locomotion of lizards on inclines and perches: hindlimb kinematics of an arboreal specialist and a terrestrial generalist. Journal of Experimental Biology 207: 233-248.

Hildebrand, M. 1966. Analysis of symmetrical gaits of tetrapods. Folia Biotheorethica 6: 9-22.

Hildebrand, M. 1985. Walking and running. Pp. 38-57 in M. Hildebrand, D. M. Bramble, K. F. Liem and D. H. Wake (eds.), Functional Vertebrate Morphology. Cambridge. Harvard University Press.

Jenkins Jr., F. A. and J. E. Goslow Jr. 1983. The functional anatomy of the shoulder of the savannah monitor lizard (Varanus exanthematicus). Journal of Morphology 175: 195-216.

Kohlsdorf, T., R. S. James, J. E. Carvalho, R. S. Wilson, M. Dal Pai-Silva, and C. A. Navas 2004. Locomotor performance of closely related Tropidurus species: relationships with physiological parameters and ecological divergence. Journal of Experimental Biology 207: 1183-1192. 
Kramer, D. L. and R. L. Mclaughlin 2001. The behavioral ecology of intermittent locomotion. American Zoologist 41: 137-153.

Marey, E. J. 1891. La Machine Animale. 5th ed. Paris, F. Alcan.

Martin, J. 1996. Effect of recent feeding on locomotor performance of juvenile Psammodromus algirus lizards. Functional Ecology 10: 390-395.

Mitchell, G. S., T. T. Gleeson and A. F. Bennett 1981. Ventilation and acid-base balance during graded activity in lizards. American Journal of Physiology 240: R29-R37.

Pellegrino, K. C. M., M. T. Rodrigues, Y. YonenagaYassuda, and J. W. Sites Jr. 2001. A molecular perspective on the evolution of microteiid lizards (Squamata, Gymnophthalmidae), and a new classification for the family. Biological Journal of the Linnean Society 74: 315-338.

Pridmore, P. A. 1994 (1995). Submerged walking in the epaulette shark Memiscyllium ocellatum (Memiscyllidae) and its implications for locomotion in rhipidistian fishes and early tetrapods. Zoology Analysis of Complex Systems 99: 278-297.

Reilly, S.M. and M. L. Delancey 1997a. Sprawling locomotion in the lizard Sceloporus clarkii: quantitative kinematics of a walking trot. Journal of Experimental Biology 200: 753-765.

Reilly, S.M. and M. L. Delancey 1997b. Sprawling locomotion in the lizard Sceloporus clarkii: the effects of speed on gait, hindlimb kinematics, and axial bending during walking. Journal of Zoology 243: 417-433.

Renous, S., E. Höfling and J.-P. Gasc 1995. Analysis of the locomotion pattern of two microteiid lizards with reduced limbs, Calyptommatus leiolepis and Nothobachia ablephara (Sauria, Gymnophthalmidae). Zoology - Analysis of Complex Systems 99: 21-38.

Renous, S., E. Höfling and J.-P. Gasc 1998. Respective role of the axial and appendicular systems in relation to the transition to limblessness. Acta Biotheoretica 46: 141156.

Renous, S., E. Höfling and J.-P. Gasc 1999. On the rhythmical coupling of the axial and appendicular systems in small terrestrial lizards (Sauria: Gymnophthalmidae). Zoology - Analysis of Complex Systems 102: 31-49.

Rocha, P. L. B. 1998. Uso e partição de recursos pelas espécies de lagartos das dunas do Rio São Francisco,
Bahia (Squamata). Unpublished Ph.D. Thesis. Universidade de São Paulo, Brazil. 108 pp.

Rodrigues, M. T. 1991a. Herpetofauna das dunas interiores do Rio São Francisco, Bahia, Brasil. I. Introdução à área e descrição de um novo gênero de microteiídeos (Calyptommatus) com notas sobre sua ecologia, distribuição e especiação (Sauria, Teiidae). Papéis Avulsos de Zoologia, São Paulo 37: 285-320.

Rodrigues, M. T. 1991b. Herpetofauna das dunas interiores do Rio São Francisco, Bahia, Brasil. II. Psilophthalmus: um novo gênero de microteiídeos sem pálpebra (Sauria, Teiidae). Papéis Avulsos de Zoologia, São Paulo 37: 321-327.

Rodrigues, M. T. 1991c. Herpetofauna das dunas interiores do Rio São Francisco, Bahia, Brasil. III. Procellosaurinus: um novo gênero de microteiídeos sem pálpebra, com a redefinição do gênero Gymnophthalmus (Sauria, Teiidae). Papéis Avulsos de Zoologia, São Paulo 37: 239-342.

Rodrigues, M. T. 1995. Filogenia e história geográfica de uma radiação de lagartos microteiídeos (Sauria, Teioidea, Gymnophthalmidae). Unpublished Thesis (Livre-Docência). Universidade de São Paulo, Brazil. $92 \mathrm{pp}$.

Rodrigues, M. T. 1996. Lizards, snakes, and amphibians from the Quaternary sand dunes of the middle Rio São Francisco, Bahia, Brazil. Journal of Herpetology 30: 513-523.

Trouillod, W., A. Delisle and D. L. Kramer 2004. Head raising during foraging and pausing during intermittent locomotion as components of antipredator vigilance in chipmunks. Animal Behaviour 67: 789797.

Van Damme, R., P. Aerts and B. Vanhooydonck 1998. Variation in morphology, gait characteristics and speed of locomotiuon in two populations of lizards. Biological Journal of the Linnean Society 63: 409427.

Van Damme, R., B. Vanhooydonck, P. Aerts and F. De Vree 2003. Evolution of lizard locomotion: context and constraint. Pp. 267-282 in V.L. Bels, J.P. Gasc and A. Casinos (eds.), Vertebrate Biomechanics and Evolution. Oxford. BIOS Scientific Publishers Ltd.

Wang, T., D. F. Carrier and J. W. Hicks 1997. Ventilation and gas exchange in lizards during treadmill exercise. Journal of Experimental Biology 200: 2619-2639.

Weinstein, R. B. and R. J. Full 1999. Intermittent locomotion increases endurance in a gecko. Physiological Zoology 72: 732-739. 